\title{
Parametric optimization while turning Ti-6Al-4V alloy in Mist-MQCL (Green environment) using the DEAR method
}

\author{
Vennela V. K. Lakshmi ${ }^{1, *}$, Kambagowni Venkata Subbaiah ${ }^{2}$, Arun Vikram Kothapalli ${ }^{1}$, and Kilparthi Suresh ${ }^{1}$ \\ ${ }^{1}$ Department of Mechanical Engineering, GITAM Institute of Technology, India \\ 2 Department of Mechanical Engineering, Andhra University, India
}

Received: 26 July 2020 / Accepted: 18 October 2020

\begin{abstract}
Sustainability in any production emphasizes green-manufacturing techniques, improvement in quality with energy-efficient techniques, and environment-friendly processes. Titanium machining productivity is greatly influenced by speed, as high cutting velocity raises the temperatures in the shear zone and heat, owing to its low thermal conductivity. Hence in this work, an attempt is made to increase productivity by exploring the efficacy at transition speed for titanium alloy machining. Water-soluble lubricant is mist-sprayed as aerosols at a near-zero temperature in minor quantity, to minimize the temperatures generated during the cutting process at increased speed. Besides, an optimal decision variable vector optimizes multi-goals of machining Titanium grade 5 alloys under Minimum quantity cooling lubrication explored in this study in transitional speed zones. The response goals are the optimization of "vibration, surface quality, tool wear rate, and Material removal rate." Multi goal optimization achieved by hybrid Taguchi coupled with Data Envelopment Analysis based Ranking (DEAR). The tool wear is very rapid at velocities of $200 \mathrm{~mm} / \mathrm{min}$. DEAR technique uses computed Multi performance rank index (MPRI) to predict the best data set at: (velocity, feed, doc) at $(120 \mathrm{~mm} / \mathrm{min}$, $0.2 \mathrm{~mm} / \mathrm{rev}, 1.0 \mathrm{~mm}$ ). In this setting, the responses are compared in dry, flood, and MQL environment. It is observed a 30\%,60\%, 40\% improvement in surface finish, tool life, and vibrations compared to a dry environment and $13 \%$ and $3 \%$ of roughness and tool wear rate compared to a flood environment. Thus MQCL can be adopted for Ti6Al4V at transitional speeds.
\end{abstract}

Keywords: MQCL / machining / Titanium alloy / Ti6Al4V / optimization / vibrations / surface finish / DEAR

\section{Introduction}

Sustainable process the prime driving factors are embracing methods and technologies that are (1) frugal, (2) results in minimum or zero waste by-product, and (3) eco friendly. Ti-6Al-4V, an $\alpha+\beta$ titanium grade-5 titanium alloy, has a wide range of applications in the aeronautical industry ranging from compressor disc to frame and structures. In the automobile industry, the applications include frame structures, armor, springs for suspension, inlet and outlet valves, and connecting rods [1]_-biomedical applications in hip joints, dental implants, and consumer industry applications such as eyeglass frames. The alloy has unique properties like high strength to density advantage, inert at high temperatures, and corrosion resistance. To improve 'Material Removal Rate' (MRR), a measure of productivity, machining at high cutting velocities employed in the

\footnotetext{
* e-mail: lakshmi.vennela@gmail.com
}

industry. However, high-speed machining (HSM) when used while cutting low thermal conductivity materials such as Ti6Al4V is challenging because thermal stress develops due to temperatures rise. As cutting velocities increase, the temperature rises rapidly at the cutting zone. Since alloy capability of conduction is low, the heat generated at the interaction zone nearly $80 \%$ transferred to the tool. Due to which the tool wear (Tw) is rapid at high speeds [2]. The lubricant application in huge quantities at rates of 160 $200 \mathrm{ml} / \mathrm{s}$ called flood environment in cutting terminology employed to mitigate the temperature at the cutting zone [3]. Reducing Tw, and surface improvement by $30 \%$ was observed while machining with low and transition speeds $45-135 \mathrm{~m} / \mathrm{min}$, using water-based, servo cut $\mathrm{S}$ grade coolant (carries additives that inhibit microbial growth) and aluminum oxide + TiC. At high speeds, water-based servo coolant aids improved surface finish significantly [4]. The usage and disposal or reuse of lubricants used deviate our sustainable goal. It involves the cost of pumping, recycling, or removal, and they are hazardous to Mother Nature and 
life. This threat to ecology has driven the industry to explore the alternatives to voluminous lubricant usage to frugal methods like 'Minimum Quantity Lubrication' (MQL), 'Minimum Quantity Cooling Lubrication' (MQCL), applications in the form of mist aerosols.

\section{Literature review}

Dry machining of Ti6Al4V at high speeds results in high temperatures limiting tool life. Use of coated tools increases tool life over uncoated tools. Dry machining, the optimum speed is $60 \mathrm{~m} / \mathrm{min}$ for optimum tool wear. At $90 \mathrm{~m} / \mathrm{min}$, the tool wear is very high, and tool life is one-fifth of that at $60 \mathrm{~m} / \mathrm{min}$ [5]. A few studies reported high speed ranges $80-150 \mathrm{~m} / \mathrm{m}$ using uncoated H13 grade insert [6] and speed rates of $150-200 \mathrm{~m} / \mathrm{min}$ with coated carbide cutting inserts [7]. Tool-wear has an impact on these surface finish and vibrations. Tool-wear is a very influential factor at high speeds that affect surface integrity [7]. Many studies report that the optimum speeds in dry machining of Ti6Al4V are less than $60 \mathrm{~m} / \mathrm{min}[8,9]$. Hence in dry machining, the speeds are constrained for a tool life goal, so productivity is less. This encouraged to explore other methods that would improve productivity, reducing the temperature at shear zones.

The employment of cutting fluids aid in the reduction of cutting-temperatures, and provide better lubrication. Flood lubrication and dry machining were compared over speed ranges of $45-130 \mathrm{~m} / \mathrm{min}$ and depth of cut (doc) $0.75 \mathrm{~mm}$ and observed $30 \%$ less tool wear in flood environment [3,4]. Lubricant application at high pressures $(10-20$ bar) and its effect on tool wear was studied [10]. Tool-life and surface-finish improved as the jets at highpressure aid in the momentum gain and better heat transfer rates. Hence higher speeds employed in pressure applied lubrication strategy [11-14]. Though these methods improved surface finish and tool-life, the process costs high as the pump's power consumption is high for Ti6Al4V alloy compared to the reduction in forces achieved compared to dry. The disposal of lubricants in large quantities poses a threat to the environment. In order to overcome the disadvantages of the flood lubrication system, the MQL strategy is explored by many researchers.

Tool life increased in the MQL cutting environment, cutting velocity of the tool is a prime factor affecting tool wear $[2,15]$. Application of MQCL with vegetable oil as a lubricant reduces surface roughness and offers better tool life. The lubrication provided by vegetable-based oil and cooling provided due to air pressure application at the tooltip aided in decreased tool wear. Experimentation carried at a constant depth of cut (doc) value $0.5 \mathrm{~mm}$ and reported reduced surface roughness and tool wear [8].

MQCL, the lubrication, is significant as the built-up

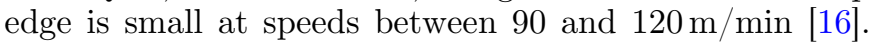
Comparative analysis using different lubrication techniques in the machining of Ti6Al4V alloy was investigated. Dry machining, flood cooling, MQL, MQCL, and cryogenic cooling were compared at various cutting speeds (90 and $120 \mathrm{~m} / \mathrm{min}$ ) and feeds $(0.1,0.2 \mathrm{~mm} / \mathrm{rev})$. Machining using MQL/MQCL were better at lower cutting speeds, cryogenic cooling was a better option at higher cutting speeds over $90 \mathrm{~m} / \mathrm{min}$. Further, vegetable oils, rapeseed oil were studied as use of Cutting fluids, were applied in MQL and MQCL environments. MQCL gave a better performance in terms of tool wear. MQCL uses cutting fluids with reduced temperatures and hence helps in better cooling of the machining zone. It has all the advantages of MQL, with the combined effect cooling lubricant [16]. The sub-zero temperature employed in MQCL while milling of Ti Grade 5 alloy proved useful at $90 \mathrm{~mm} / \mathrm{min}$ speed, offering good surface finish and chip morphology. The temperature of the airstream had a profound impact on reducing the cutting zone temperatures [17].

The cryogenic cooling effect on response temperature and tool-wear showed that the tool-wear is minimum and surface finish best compared to dry and flood cooling. Cryogenic cooling has decreased surface roughness by around two times; For tool wear, the most influential variable is speed [11]. An analysis of the literature, more works are reported in speed ranges of $40-120 \mathrm{~m} / \mathrm{min}$, and tool wear, surface roughness are two parameters widely investigated while machining using Lathe. There are very few works that examined the effect of vibrations on surface roughness.

Multi-response optimization of wear of tool, MRR, and surface quality reported using a combination of 'Analytical Hierarchy Process' (AHP) and Grey-relational-analysis (GRA) techniques. A trade-off is mandatory between surface finish, productivity, and cutting power, hence in rough cuts, high productivity factors, and finish cut high surface finish factors chosen $[12,13]$. GRA technique employed for studies on best combination input parameter prediction for cutting zone temperature, quality, and MRR for low machinability material [6]. GRA is applied on machinability studies on hardened steels in a dry and wet environment and wet machining conditions, reported the roughness and temperature are low in wet machining [18]. 'Data envelopment analysis based ranking' (DEAR) technique is employed to optimize parameters of electric discharge machining of Ti6Al4V alloy [19]. The effect of texture tool while machining SS316 steel. MRR, Surface roughness (SR), and Tw are optimized using the entropy technique. Spark erosion technique is used for texture creation on the WC tool [20]. Minimization of power consumption during the machining process of nickel alloy with a PVD coated Ti-N-Al-Si tool employing Taguchi based signal-to-noise (SN) ratio is explored [21]. Response surface methodology (RSM) based models are fed to JAYA and Teaching learning-based algorithm (TLBO) for optimization and compared with the genetic algorithm (GA) [22]. Optimization of milling parameters while machining Ti6Al4V alloy using 'Technique for Order Preference by Similarity to Ideal Solution' (TOPSIS) was explored [23]. GRA, coupled with PCA, 'principal component analysis,' is proposed to optimize radial force, power, and friction simultaneously [24].

Much literature available in studies that optimize single goal in machining studies of Ti6Al4V alloy, in varying cutting conditions but since productivity and tool life goals are conflicting, multi-goal optimization is a must. To the authors' knowledge, not much work reported on the 


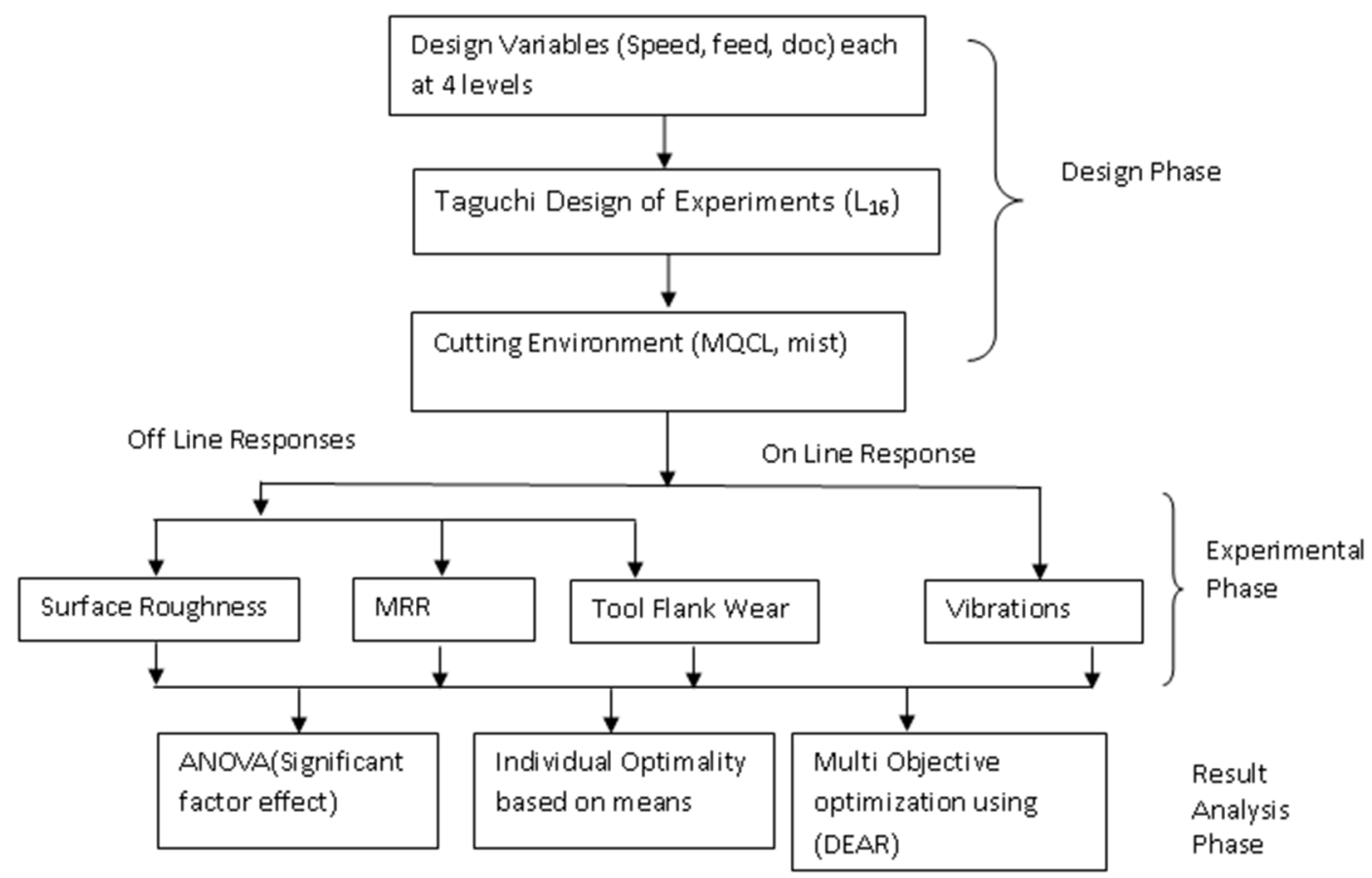

Fig. 1. Experimentation Flow diagram.

influence of cutting variables on the workpiece vibration. MQCL, though significant, not much work in turning at high speeds is examined $[9,25]$. Hence this work focus on the selection of turning process parameters that simultaneously optimize surface quality, tool wear rate, vibration using the Taguchi-DEAR technique within boundary constraints. The turning environment chosen for the current study is MQCL. In transition and high-speed ranges of Ti6Al4V, employing the MQCL method also achieves the cleaner production, near-zero waste of sustainability goals as lubricant used is decreased by $90 \%$ and cooling is done by Mist spray of pressurized air lubricant mixture in the form of aerosols. The aerosols sprayed are at a temperature of near-zero (2-3 deg centigrade). A chamber for a mix of lubricant and pressurized air is designed to decrease the exit air lubricant mixture's temperature via a valve. The cutting speed recommended for a dry cut on Ti6Al4V is $60 \mathrm{~mm} / \mathrm{min}$. In this study, higher speed cutting is investigated with the hypothesis that MQCL provides necessary cooling and lubrication action and maintains less temperature, good part quality, vibrations in the employed speed ranges.

\section{Experimental procedure}

Taguchi based array for three parameters, each at four levels $\mathrm{L}_{16}$ orthogonal array is selected, and experimentation performed, based on the array $[19,21,26,27]$. The experimental flow adopted for the current work is shown in Figure 1.

The experimental setup, including turn-mill center, lubricant flow tank, air pressure tank, nozzle, an online vibration measuring device (laser doppler vibrometer) vibrometer, temperature measuring equipment, and the offline tool wear measuring device is shown in Figure 2. The parameter's influence on the responses are assessed based on the mean effect plots of responses; a significant deviation from the mean refers to a considerable impact on the response function; any variable with minor deviation from the average has less effect on the factor. The optimal setting of the parameter for least surface roughness, vibrations (Vib), tool wear rate (Twr) is taken from the mean plots employing the decision of smaller-the-better in choice of Vib, SR, Twr; larger-the-better for MRR. As outputs are not independent, and a correlation exists between them, optimization of a single objective may prove costly for other goals. Due to conflicting objectives in the study, 'multi-criteria' optimization simultaneously optimizes all objective functions, and the optimum combination is chosen. The DEAR method is considered to select optimal parameter settings within the experimentation framework to optimize all the output responses simultaneously.

The step by step procedure for the DEAR technique is given below. The DEAR method is used for a discrete type of data.

Step 1: For a given response, based on experiments, a vector of weights $\mathrm{Wi}$ is computed. If the output is maximum, the better criteria like MRR, then the weight vector for $i$ th output, is the ratio of the magnitude of the $i$ th experimental run to the sum of all magnitudes of the response function. For minimum, the best criteria like Ra, Twr weights are computed based on the reciprocal of output values.

For ith experimental run

$$
\mathrm{W}_{\mathrm{SRi}}=1 / \mathrm{SRi} / \sum_{\mathrm{i}=1}^{\mathrm{n}} 1 / \mathrm{SRi}
$$



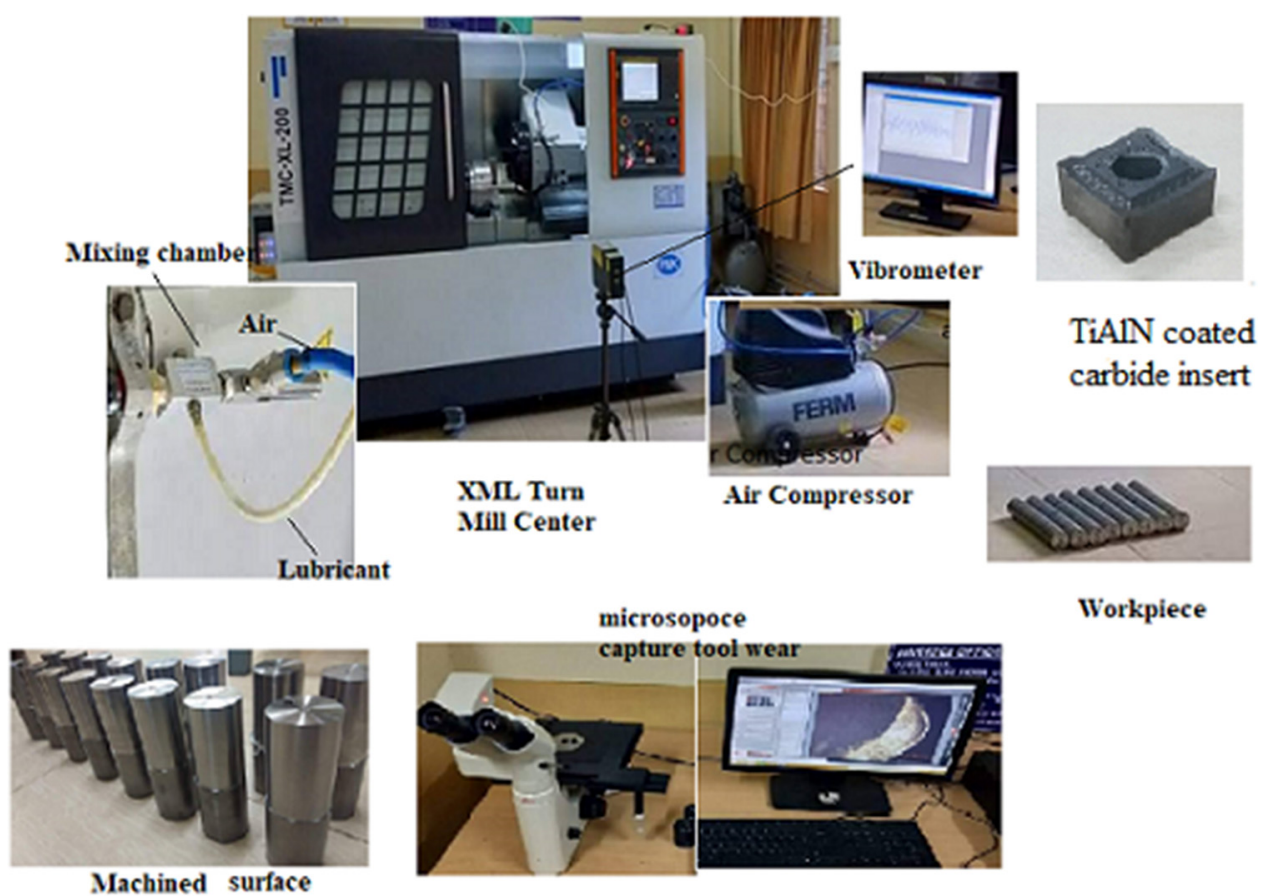

Workpiece

Fig. 2. Fanuc-0i Control CNC Turn-Mill-MQCL setup, response measuring devices, and Ti6Al4V work-pieces.

Table 1. Composition weight $\%$ of elements in Ti-6Al-4V.

\begin{tabular}{llll}
\hline Titanium $(\mathrm{Ti})$ & Iron $(\mathrm{Fe})$ & Vanadium $(\mathrm{V})$ & Aluminium $(\mathrm{Al})$ \\
\hline 89.29 & 0.23 & 4.39 & 6.01 \\
\hline
\end{tabular}

$\mathrm{W}_{\mathrm{Ra}}$, weight of SR: Minimum is best

$$
\mathrm{W}_{\mathrm{Vibi}}=\frac{1}{\mathrm{Vibi}} / \sum_{\mathrm{i}=1}^{n} 1 / \mathrm{VIBi}
$$

$\mathrm{W}_{\text {Vibi }}$, weight of Vib: Minimum Best

$$
\mathrm{W}_{\mathrm{MRRi}}=\mathrm{MRRi} / \sum_{\mathrm{i}=1}^{\mathrm{n}} \mathrm{MRRi}
$$

$\mathrm{W}_{\text {mrri }}$, Weight of MRR: Maximum Best

$$
\mathrm{W}_{\text {Twri }}=\frac{1}{\text { Twri }} / \sum_{\mathrm{i}=1}^{n} \frac{1}{\mathrm{Twri}}
$$

$\mathrm{W}_{\text {Twri }}$, Weight of Twr: Minimum best

Step 2: Weighted response for each output is computed as a product of weights and response magnitude.

$$
\begin{gathered}
\mathrm{wSR}_{\mathrm{i}}=\mathrm{SR}_{\mathrm{i}} * \mathrm{~W}_{\mathrm{SRi}} \\
\mathrm{wMRR}_{\mathrm{i}}=\mathrm{MRR}_{\mathrm{i}} * \mathrm{~W}_{\mathrm{MRRi}} \\
\mathrm{wVib}_{\mathrm{i}}=\mathrm{Vib}_{\mathrm{i}} * \mathrm{~W}_{\mathrm{Vibi}} \\
\mathrm{wTwr}_{\mathrm{i}}=\mathrm{Twr}_{\mathrm{i}} * \mathrm{~W}_{\mathrm{Twri}}
\end{gathered}
$$

Step 3: MRPI is the ratio of the sum of weighted response with higher the better goal to the sum of responses with lower the better goal.

$$
\mathrm{MRPI}={ }^{\mathrm{wMRR}} \mathrm{i} /\left(\mathrm{wVib}_{\mathrm{i}}+\mathrm{wTwr}_{\mathrm{i}}+\mathrm{wSR}_{\mathrm{i}}\right)
$$

MRPI for each level is computed, and the best-ranked level of input is chosen as the best performing combination for simultaneous optimizing of all responses within the boundary conditions $[19,27]$.

\subsection{Experimentation, tool, and Workpiece details}

The work material is grade 5 Ti6Al4V alloy of circular cross-section $28 \mathrm{~mm}$ radius and length $200 \mathrm{~mm}$. Table 1 summarizes the properties and compositions of alloy used. The cutting tool employed is TiAlN coated via a physical vapor deposition method on carbide rhombic shaped, nose radius of $0.8 \mathrm{~mm}$ insert ('Kennametal MAKE CNMG120408M5 KC5010'). The coating selected for this study provides better heat and wear-resistant while machining difficult to cut metals while mist cooling $[8,15,24,28]$. One explanation given is the formation of a protective insulating layer, $\mathrm{Al}_{2} \mathrm{O}_{3}$ is reported to form on the tool for TiAlN coated [29]. 
Table 2. L-16 OA design and experimental measure responses.

\begin{tabular}{|c|c|c|c|c|c|c|c|}
\hline \multirow[t]{2}{*}{ No. } & \multicolumn{3}{|c|}{ Input variables } & \multicolumn{4}{|c|}{ Responses } \\
\hline & $V_{\mathrm{c}}(\mathrm{m} / \mathrm{min})$ & Feed $(\mathrm{mm} / \mathrm{rev})$ & Doc $(\mathrm{mm})$ & $\mathrm{SR}(\mu \mathrm{m})$ & $\operatorname{Vib}(\mu \mathrm{m})$ & Wear rate (Twr) & $\operatorname{MRR}\left(\mathrm{mm}^{3} / \mathrm{s}\right)$ \\
\hline 1 & 80 & 0.05 & 0.25 & 0.34 & 25.5 & -6.51505 & 0.999 \\
\hline 2 & 80 & 0.10 & 0.50 & 0.99 & 32.9 & -6.13184 & 3.998 \\
\hline 3 & 80 & 0.15 & 0.75 & 1.42 & 60.7 & -6.00684 & 8.899 \\
\hline 4 & 80 & 0.20 & 1.00 & 2.31 & 70.9 & -5.85437 & 15.999 \\
\hline 5 & 120 & 0.05 & 0.50 & 0.33 & 22.8 & -6.50554 & 2.999 \\
\hline 6 & 120 & 0.10 & 0.25 & 0.98 & 26.5 & -6.06316 & 2.999 \\
\hline 7 & 120 & 0.15 & 1.00 & 1.09 & 41.2 & -5.82361 & 17.998 \\
\hline 8 & 120 & 0.20 & 0.75 & 1.71 & 44.7 & -5.75617 & 17.998 \\
\hline 9 & 160 & 0.05 & 0.75 & 0.42 & 23.4 & -5.76877 & 5.999 \\
\hline 10 & 160 & 0.10 & 1.00 & 0.61 & 34.4 & -5.32692 & 15.999 \\
\hline 11 & 160 & 0.15 & 0.25 & 0.63 & 19.0 & -5.26902 & 5.9999 \\
\hline 12 & 160 & 0.20 & 0.50 & 1.07 & 41.4 & -5.53543 & 15.999 \\
\hline 13 & 200 & 0.05 & 1.00 & 0.52 & 32.2 & -5.65161 & 9.9990 \\
\hline 14 & 200 & 0.10 & 0.75 & 0.51 & 32.5 & -5.29743 & 14.999 \\
\hline 15 & 200 & 0.15 & 0.50 & 1.16 & 34.1 & -5.11786 & 14.999 \\
\hline 16 & 200 & 0.20 & 0.25 & 1.09 & 27.9 & -5.01203 & 9.9999 \\
\hline
\end{tabular}

Water-based lubricant Servo oil in 1 of 20 times ratio is used in MQL is mixed with air at 5 bar pressure from the compressor tank in a designed chamber. The output from the nozzle is cooled to 2 deg centigrade aerosol of lubricant. The aerosols are sprayed on the tool-workpiece interaction zone near the tool tip targeted. The lubricant flow rate is measured and adjusted to $30 \mathrm{ml} / \mathrm{min}$ though out the work. A small amount of lubricant and cold air combined to provide both lubrication and cooling effect at the shear zone is called MQCL.

The liquid water performs best as a heat removing agent. Compared to neat oil, water is a better agent for cooling as the convective heat transfer rate is high, and the heat removal rate is two and a half times more than oils. Water-soluble oils' effectiveness as the lubricant is reported better than neat oils and synthetic oils $[4,30]$. Therefore water-soluble oil is used as a lubricant in the current study for MQCL application.

Experiments of conventional turning are carried on "XL200 TMC" spindle speed maximum 6000 RPM, turnmill center. Taguchi experimental design is the basis for experimentation, and every input factor is tested at four levels. For three factors, at level four levels of input variables, the minimum presented trails are 10,16 out of which L16 was selected for the study.

The inputs chosen for studies are workpiece velocity, feed-in axial direction, depth-of-cut (doc). The levels of factors that can be tuned for optimization are determined from findings reported [7,21], and tool makers recommended ranges (doc $0.25 \mathrm{~mm}-1.0 \mathrm{~mm}$; axial feed rate, $0.05-0.2 \mathrm{~mm} / \mathrm{rev}$; tool velocity, $80-200 \mathrm{~m} / \mathrm{min}$ ). The cutting speed chosen is a little higher than recommend as this study wants to explore the possibility of improving productivity in the MQCL environment at a higher speed.
Experiments repeated twice, a fresh cutting tool insert is used for every experiment, and average values for each response are tabulated in Table 2.

\section{Experimental measures of outputs and discussion}

Wear on the tool flank face is measured with an inverted optical microscope by LEICA to capture the optical micrograph. Image $\mathrm{J}$ software is used to measure the $\mathrm{Tw}$ on flank face from micrograph as per the standard prescribed by 'ISO: 3685-1993'. The wear measured is maximum flank wear after each experimental run shown in Figure 6. To compare flank wear, the time taken to reach the limiting value of $0.3 \mathrm{~mm}$ maximum tool wear under different machining conditions is a criterion often used. In this study, the tool wear is measured after each experimental run. Therefore limiting criteria cannot be adopted. Here normalized tool flank wear rate (Twr) is employed to assess flank wear. The normalized wear rate parameter considers the 'spiral length for turning' as suggested [26]. Flank Wear is converted to wear rate with the help of equation (10) [26].

$$
\mathrm{T}_{\mathrm{wr}}=\log \frac{\mathrm{Tw}}{\mathrm{lc}}
$$

where $\mathrm{Tw}$ is maximum flank wear in $\mathrm{mm}$, lc is the total length of cut in $\mathrm{mm}$, i.e., 'spiral length.'

SJ-301 diamond tip roughness tester is used to measure surface roughness $\mathrm{Ra}, \mathrm{Rz}, \mathrm{Rq}$, and Guass filter applied. The measured surface profile for speeds of $80 \mathrm{~m} / \mathrm{min}$, $0.05 \mathrm{~mm} / \mathrm{rev}$ feed, doc $0.25 \mathrm{~mm}$ is Ra $0.34 \mu \mathrm{m}, \mathrm{Rz} 2.16 \mu \mathrm{m}$, 


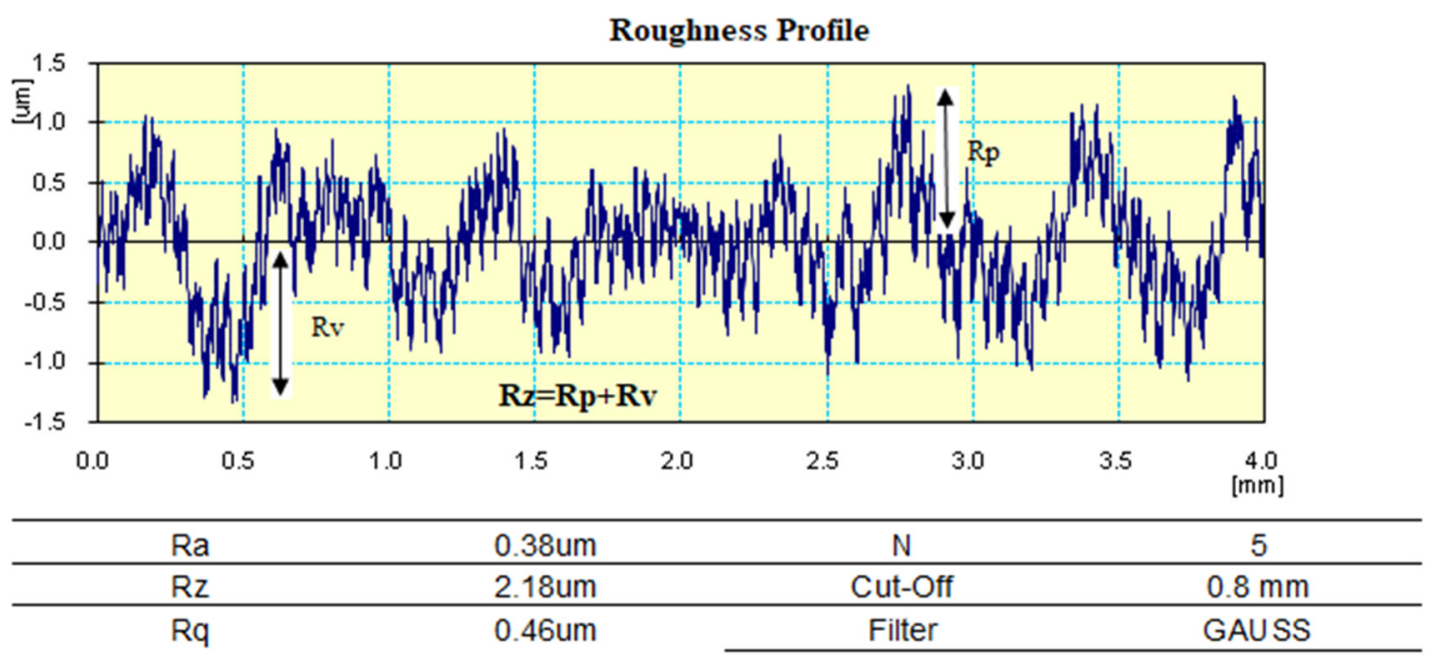

Fig. 3. Roughness profile for experimental run 1.

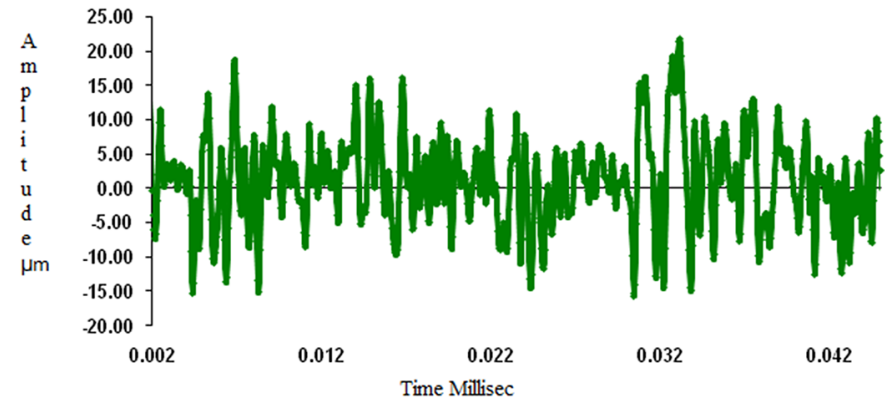

Fig. 4. Vibration Time vs. Amplitude filtered profile.

and Rq $0.46 \mu \mathrm{m}$, as shown in Figure 3. The cut-off length of $0.8 \mathrm{~mm}$ is chosen as the maximum $\mathrm{SR}$ for experimental runs is less than 2.84 microns.

Due to high spindle speeds, vibrations are observed in the rotary workpiece. Ti6Al4V low modulus of elasticity causes springs back effect of the workpiece resulting in vibrations during cutting [25]. These vibrations are captured in real-time using an LDV noncontact, based on the acoustic-optic emission principle, while machining. The captured signals transformed using a fast Fourier Transform (FFT) for amplitude Vs. Time as shown in Figure 4. As per 'ISO-10816' standards for rotatingworkpiece, the amplitude of vibration up to $20 \mu \mathrm{m}$ has a negligible impact on Tw. Tw effects when vibration amplitude in the workpiece ranges from 20 microns to 60 microns, and vibration amplitude beyond 60 microns needs attention [31]. From the results tabulated in Table 2, one can observe that as vibration amplitude is high, so is the surface roughness. Hence vibration amplitude and surface roughness do have an impact on one another and are positively correlated, as shown in Figure 7.

\subsection{Effect of speed}

The machining ranges for various metals in the conventional, transitional, and high-speed machining (HSM) ranges. For titanium alloy, $60-120 \mathrm{~m} / \mathrm{min}$ is termed as transitional and speeds greater than $120 \mathrm{~m} / \mathrm{min}$ HSM range [32]. In this study, $80-200 \mathrm{~m} / \mathrm{min}$ spindle speeds are employed to explore the effect of process parameters in the MQCL environment.

The effect of process variables on SR, Twr, MRR, Vib is depicted in Figure 5 shows. Till the speed level-3, surface finish and Vib decrease with the speed increase, whereas MRR and tool wear increase with speed. Speed is the most dominant parameter to influence the wear rate as seen from ANOVA Table 4, and a high F test statistic confirms the fact. At low speeds and high doc $(80 \mathrm{~m} / \mathrm{min}, 0.75 \mathrm{~mm})$, the vibration amplitude is high in Figure 7.

Due to high rotational spindle speeds, the rotational frequencies are high [10]. Ti6Al4V has low elasticitymodulus due to which it tends to sway away from the tool. This phenomenon leads to non-uniform cutting, rubbing action, and an increase in friction and heat [33]. This, inturn affects surface geometry; hence state parameter effects surface finish at high speeds. The surface roughness measured at all speeds is far less than the reported in the literature at speeds of $150-300 \mathrm{~m} / \mathrm{min}$ in flood environment, the minimum being in the range of 2.85 3.5 microns [34].

Speed has a profound effect on the wear of tools. Though productivity improves with speed, an increase in vibration amplitude decreases toolwear [10]. The tool coating loss is observed, and Tw is a combination of pulling off the coating on the flank face. The high tool wear rate can be attributed to the two reasons [35]: At high speed $(200 \mathrm{~m} / \mathrm{min})$ and $\mathrm{doc}(1.0 \mathrm{~mm})$, the tool penetration is more, the area of contact at the interaction zones, i.e., the workpiece - tool-tip, tool rake face-chip, and tool flank face-uncut chip(strained material), causing sliding friction. Speeds greater than $160 \mathrm{~m} / \mathrm{min}$ results in vibration amplitudes more than $30 \mu \mathrm{m}$, which affects Twr. Machining at $200 \mathrm{~m} / \mathrm{min}$ in MQCL condition, the initial cut was smooth until $30 \mathrm{~mm}$, but as time passed, combustion was noticed, indicating high heat generation and high friction. High temperatures build at the shear zone, the aerosol mist evaporated quickly, not providing the intended cooling effect or lubricity at these speeds. 

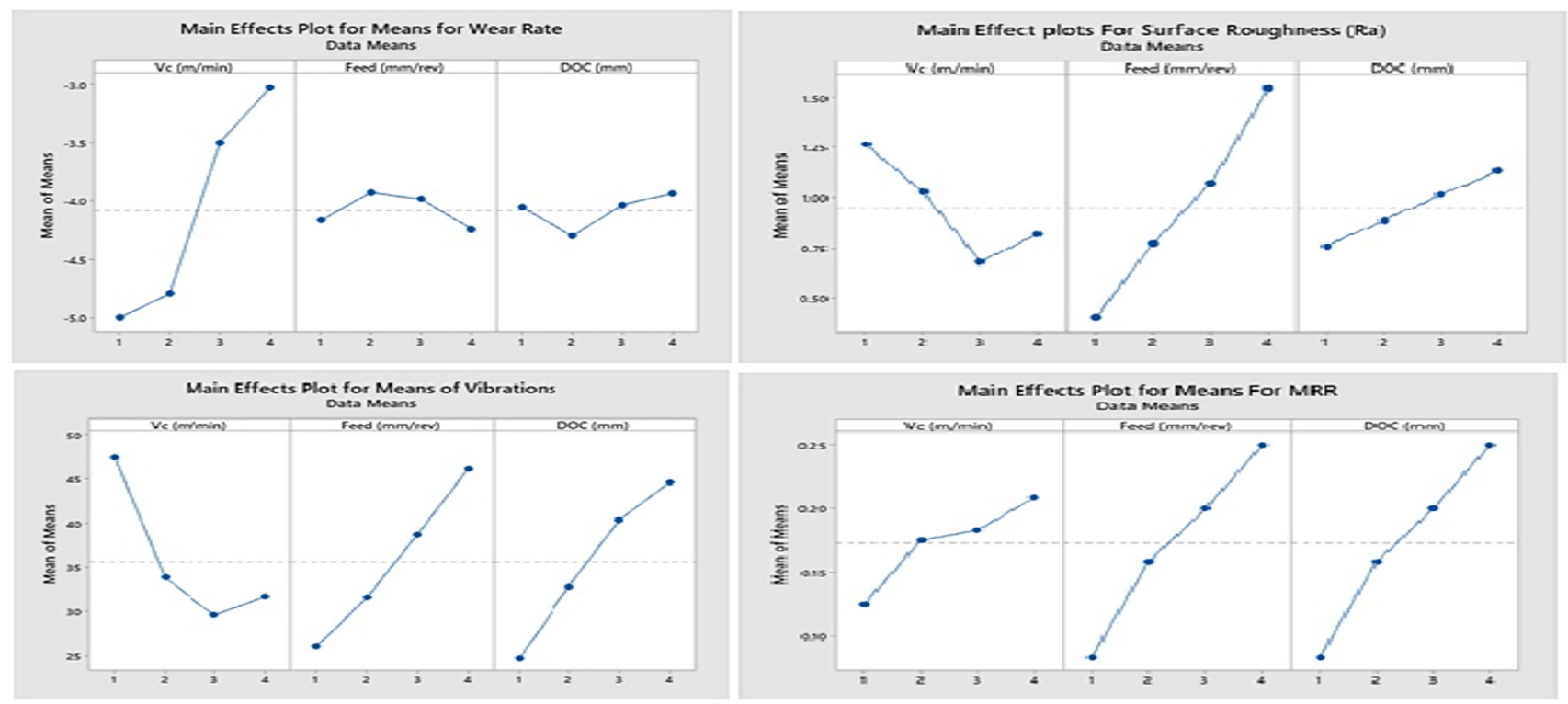

Fig. 5. Plots of Main effects of cutting variables speed, feed, a doc on SR, Twr, Vib, and MRR.

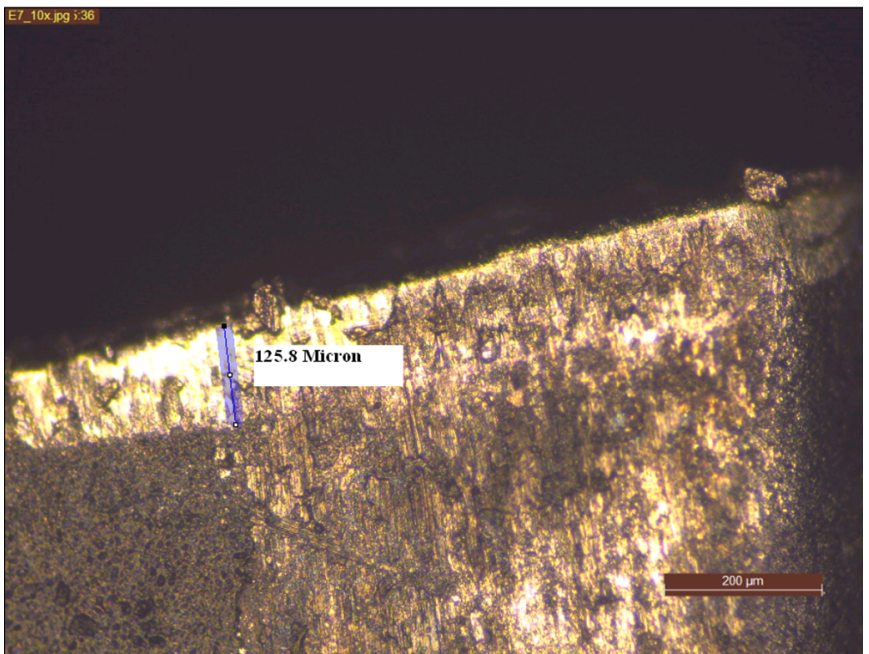

Fig. 6. Optical microscopic picture of flank wear (Tw).

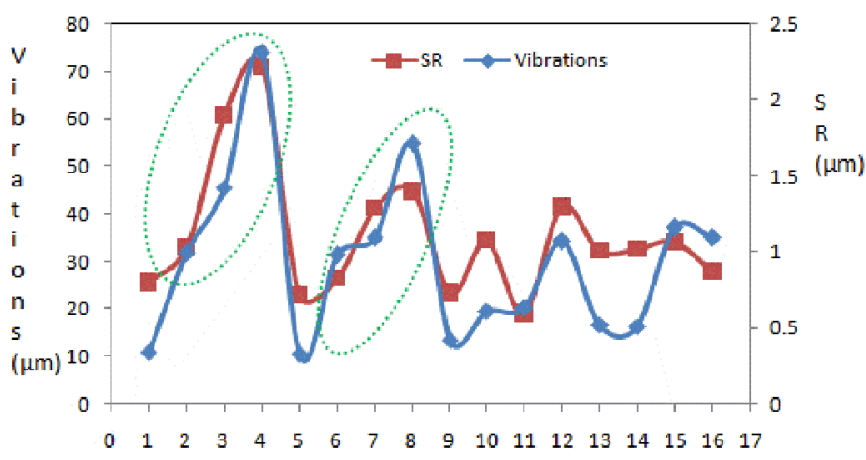

Fig. 7. The trend of SR and Vib Vs. Experimental runs.
The surface finish during MQCL turning of alloy exhibited better results than dry cut for all runs [8]. At low and medium speeds, pressurized chilled air lubricant sprayed on the tool-tip is found very useful in reducing temperature $[25,36]$. At high speeds, the lubrication is not sufficient, due to which friction between tool and workpiece increased, thereby increasing forces. The tool wear rate observed is similar to reported at speeds less $80 \mathrm{~m} / \mathrm{min}$, and low feed rates adhesive wear observed, and at high speeds, the coating is lost and sticking of workpiece material on the tool (diffusion wear) observed. At $200 \mathrm{~m} / \mathrm{min}$, the tool wear is maximum and hence tool life lower at this velocity level. Published results for machining alloy under a dry environment, the surface roughness was high compared to current results for cutting speed, feed, and doc variation under MQCL. The mean of Ra varied between 1.0 and 2.4 microns in dry cut, whereas in MQCL 0.2 to 2.31 microns for higher speeds, that is a decrease of Ra values by $25 \%$ [24].

\subsection{Effect of depth of cut}

The effect of the doc on MRR is significant as MRR increases productivity, and doc increases MRR. Still, the surface finish is affected by an increase in the doc as vibrations amplitude magnify. As doc increased, the amplitude of the workpiece's vibration increased almost linearly, and the rate of growth is high. High doc $(1.0 \mathrm{~mm})$ require more effort to penetrate the tool into the workpiece, growing shear force. Compared to flood environment, the MQCL setup is economical as pumping fluid equipment and after treatment of lubricant is avoided. When compared to the dry cutting environment, better productivity can be achieved. Hence at transition speeds, the doc is a significant parameter that decides response behavior $[3]$. 
Table 3. Analysis of variance of means-surface roughness.

\begin{tabular}{llllllll}
\hline Parameters & DoF & Sum Squares & Adj Sumsquares & Adj MS & $F$ & $P$ & Significance \\
\hline$V_{\mathrm{c}}(\mathrm{m} / \mathrm{min})$ & 3 & 0.7747 & 0.7747 & 0.25824 & 3.14 & 0.108 & $\mathrm{~S}$ \\
Feed $(\mathrm{mm} / \mathrm{rev})$ & 3 & 2.8036 & 2.8036 & 0.93454 & 11.36 & 0.007 & HS \\
DOC $(\mathrm{mm})$ & 3 & 0.3101 & 0.3101 & 0.10337 & 1.26 & 0.370 & NS \\
Residual Error & 6 & 0.4937 & 0.4937 & 0.08228 & & & \\
Total & 15 & 4.3822 & HS-high & S-Significant & NS- Not Significant \\
\hline
\end{tabular}

\subsection{Effect of feed}

From ANOVA Table 3, F-static for axial feed is high. Hence the factor positively influencing the surface roughness is feed. This trend agrees with previous works published [4]. As feed increases, vibrations vary and contribute to the surface finish [31]. With increased speed, SR, MRR, and Vib showed an increasing trend in the limits of ( 0.05 to $0.2 \mathrm{~mm} / \mathrm{rev})$ feed rate. The vibrations varied at a constant rate with varying feed. Surface roughness had a steep increase as the feed rate increase beyond $0.15 \mathrm{~mm} / \mathrm{rev}$.

The $\mathrm{Tw}$ increased gradually with an increase in feed rate from $0.05-0.1 \mathrm{~mm} / \mathrm{rev}$, a gradual decrease of $0.1-0.15 \mathrm{~mm} / \mathrm{rev}$, and a sudden decline in $\mathrm{Tw}$ at higher feed rates $(0.15-0.2 \mathrm{~mm} / \mathrm{rev})$. This trend observed is similar to the works reported by Mello et al. [7]. In the current study, tool wear is minimum for feed rates selected at the highest level $(0.2 \mathrm{~mm} / \mathrm{rev})$. This may be due to the effectiveness offered by the MQCL environment in providing the necessary cooling effect by convective heat transfer and enhanced or desired lubricity due to the high penetration of spray.

\subsection{Effect of parameters on chip morphology}

Chip surface morphologies, as observed for all cutting parameter combinations, are shown in Figure 8. The MQCL environment employed in the study works on the principle of a near-zero air stream spray in the form of mist to provide a cooling effect and enhance the heat transfer rate at the cutting zone. This MQCL technique blends the leverages offered by MQL (lubricity) and cooling by airflow (Convective heat transfer); The sub-zero/near-zero lubricant air-lubricant mixture increases lubricant viscosity and enhances the boundary lubrication at the conjunction of chip and tool [14]. The lubricant present on the workpiece exterior surface aids in inhibiting the chip upper surface micro weld formation. It prevents the chip from strengthening and aids the chip separation from the tool face, can be observed from the chip morphology, where the free surface has serrations Figure 8 (8.4).

The length of chips can be one of the parameters to assess the form of chips [14]. If chip length exceeds $100 \mathrm{~mm}$, they possess interference in the machining process and hence are undesirable. As per criteria from chips assessing the form of chips from experimental runs, 5, 13 were like a bird's nest and more than $100 \mathrm{~mm}$ length and unacceptable.
In chip morphology study zones that determine chip generation is turning are three: the shear area zone, tool and chip interface friction, and workpiece and tool flank surface-interaction friction zone.

A physical examination reveals that curl radius has an increasing tendency with an increase in feed. At $0.2 \mathrm{~mm} / \mathrm{rev}$ feed, the curl radius is maximum, refer to Figure $8(8.4,8.7,8.8,8.16)$. As a speed increase (160-200 m/min), the chip's thickness descends, and the curl radius decreases. At high speeds as doc increase, chip thickness also increases, and at very high speeds, flat ribbon-like chips, which are blue colored (indicates combustion of chips), are observed in Figure 8 (run 10, $11,12,13)$. For run 15 with the speed of $200 \mathrm{~mm} / \mathrm{min}$ and doc $0.5 \mathrm{~mm}$, the initial chip was curled as machining continued beyond $5 \mathrm{~s}$; the chips were burnt blue, which is due to high friction and temperatures material softens. The MQCL system was not efficient at this parametric condition to provide the necessary cooling as the secondary heat is high. This can be taken as a boundary condition for further study. From Figure 8 (8.10 and $8.13)$, the chips resemble a bird's nest with twirls and burnt; as of titanium alloy, the fine feather-like chips ignite fast than the sturdy chips.

Many chips are observed to be in helical structure except that at high speed, doc, and feed combinations. As observed with an increase in cutting velocity, continuous coiled spiral chips are formed. During the metal removal process by coated carbide tool for Ti-6Al-4V alloy, chips were thin string-like structures at a lower speed, feed, and doc combinations $(80 \mathrm{~m} / \mathrm{min}$, $0.01 \mathrm{~mm} / \mathrm{rev}, 0.25 \mathrm{~mm})$.

The flank portion wear on the tool and chip burnt noticed to be at the maximum for larger cutting velocities, reflecting the hardness of the workpiece material and its low-machinability. Due to the MQCL effect, the aerosols sprayed in the form of mist and water-based fluid whose latent-the heat of absorption is more the same chip burning is not observed at transition speeds and at high speeds and low depth of cuts. This occurrence may be due to the pressure air lubricant mixture could penetrate through the vapor formed by the water phase change due to heat at the shear zone, thereby cooling the workpiece and also developing a lubricating film. Thin chips, due to less area of contact, the cutting pressure is high on the workpiece, and high heat generated, moreover chip inefficient to transfer heat. The problem of adhesion arises due to high pressure. 


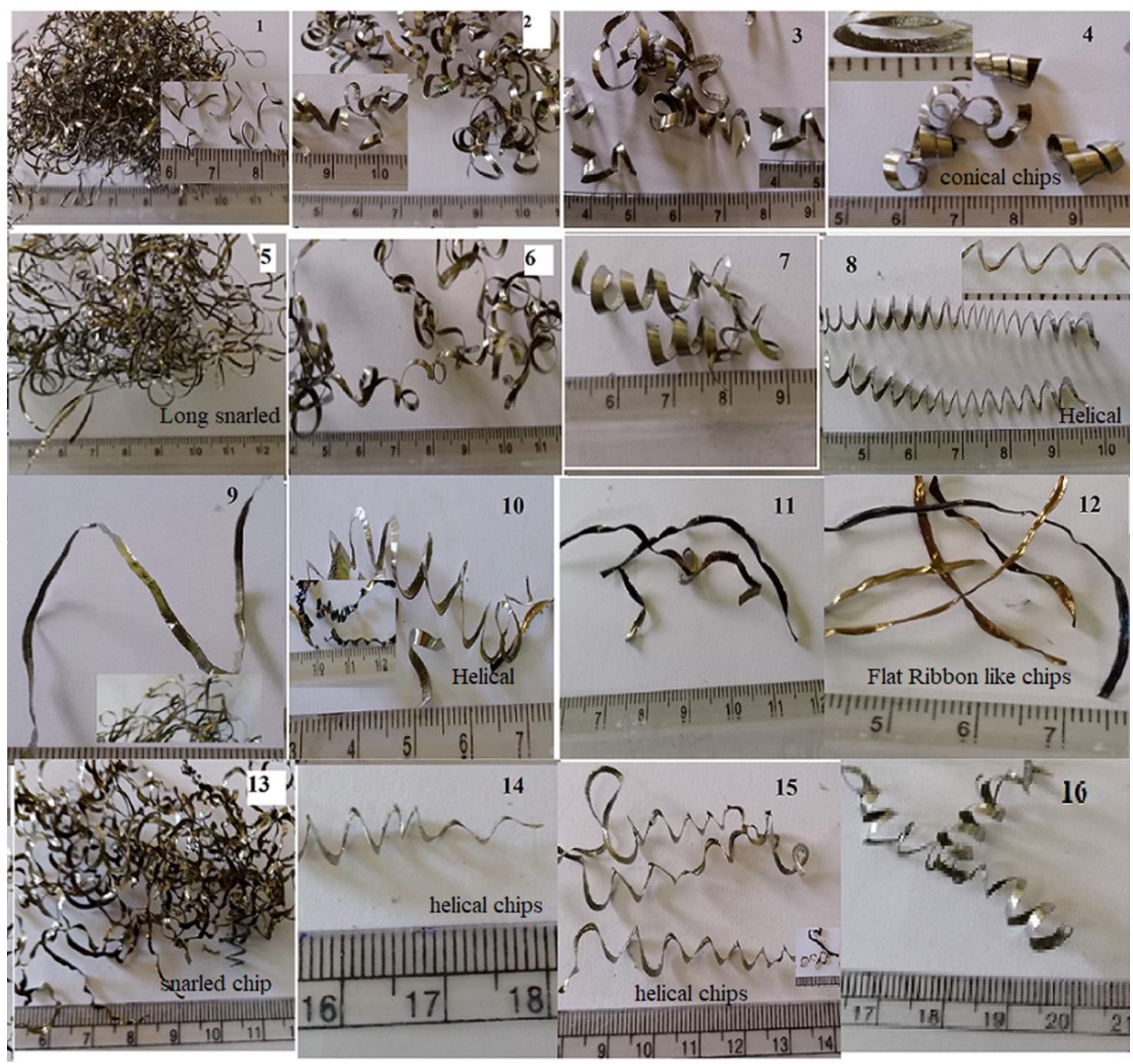

Fig. 8. Images of Chips during machining at all levels.

At a velocity of $120 \mathrm{~m} / \mathrm{min}$ and $1.0 \mathrm{~mm}$ doc, the chips were short and conical. Due to speed and doc, the shearing force is high and resulted in more concise, thicker chips. At cutting velocity (like $160 \mathrm{~m} / \mathrm{min}$ ), the lower depth of cuts (experiments 11 and 12) engraved correspondingly lesser tool-wear. On the other hand, at higher doc (like experiments 9 and 10) due to large shearing between tool and workpiece, burning of the tool flank started to emerge, and as a result of this rising tool flank wear, chips combusted, and evident from images in Figure 8 $(8.9,8.10,8.13)$.

At higher cutting velocities $(160-200 \mathrm{~m} / \mathrm{min})$, in conjunction with a higher doc (i.e., experiments 13- and 14) fire flames, change in the chip's color is observed. An explanation could be due to increased penetration of the tool into high-speed rotating hard material more metal contact with the cutting-tool, generating high friction temperatures. However, in experiments 15 and 16 , in conjunction with a smaller doc, there was no change in the color the chip as the tool has less penetration into the workpiece hence no burning.

\subsection{Optimization}

To obtain the best set of input variables that optimizes the single response by analyzing means is possible. From mean plots, the speed, feed, and doc the best input set, for best $\mathrm{SR}$ is $(160 \mathrm{~m} / \mathrm{min}, 0.05 \mathrm{~mm} / \mathrm{rev}, 0.25 \mathrm{~mm})$, best Twr is $(80 \mathrm{~m} / \mathrm{min}, 0.2 \mathrm{~mm} / \mathrm{rev}, 0.5 \mathrm{~mm})$, best Vib $(160 \mathrm{~m} / \mathrm{min}$, $0.05 \mathrm{~mm} / \mathrm{rev}, 0.25 \mathrm{~mm})$, and best MRR $(200 \mathrm{~m} / \mathrm{min}$, $0.2 \mathrm{~mm} / \mathrm{rev}, 1 \mathrm{~mm}$ ). So the best pick of any of the above goals compromises the other for example, the MRR best set is the worst choice for Twr. Set 4 maximizes productivity, has the worst tool life and, set 2 best for tool life, which hurts productivity and surface quality. A trade-off among objectives requires careful choice of parameters, a weighted response approach for multi-objective decision-making techniques studied here. The response Twri consists of negative integer values. To apply basic DEAR technique needs a strict positive non zero vector. Many ways are proposed to handle non-positive integer vectors; a simple solution proposed to handle negative data is the application of the linear translation technique is adopted here. 
Table 4. Analysis of variance of means - tool wear.

\begin{tabular}{llllllll}
\hline Parameters & DoF & Sum Squares & Adj SS & Adj MS & $F$ & $P$ & HS \\
\hline$V c(\mathrm{~m} / \mathrm{min})$ & 3 & 774640 & 774640 & 258213 & 33.38 & 0.000 & \\
Feed $(\mathrm{mm} / \mathrm{rev})$ & 3 & 26627 & 26627 & 8876 & 1.15 & 0.403 & \\
DOC $(\mathrm{mm})$ & 3 & 18696 & 18696 & 6232 & 0.81 & 0.535 & \\
Residual Error & 6 & 46413 & 46413 & 7735 & & & \\
Total & 15 & 866376 & & & & & \\
\hline
\end{tabular}

Table 5. Response weights and MRPI for DEAR method.

\begin{tabular}{|c|c|c|c|c|}
\hline Weight of SR & Weight of vib & Weight of Twr & Weight of MRR & MRPI \\
\hline 0.128734 & 0.000068787 & 0.073895 & 0.006024 & 0.132328706 \\
\hline 0.044212 & 0.000053315 & 0.071149 & 0.024096 & 2.117259298 \\
\hline 0.030824 & 0.000028897 & 0.072832 & 0.054217 & 10.7186252 \\
\hline 0.018948 & 0.000024740 & 0.071915 & 0.096386 & 33.87614877 \\
\hline 0.132635 & 0.000076933 & 0.073567 & 0.018072 & 1.190958355 \\
\hline 0.044663 & 0.000066192 & 0.069005 & 0.018072 & 1.190958355 \\
\hline 0.040156 & 0.000042575 & 0.067137 & 0.108434 & 42.87450078 \\
\hline 0.025596 & 0.000039241 & 0.068826 & 0.108434 & 42.87450078 \\
\hline 0.104213 & 0.000074961 & 0.054715 & 0.036145 & 4.76383342 \\
\hline 0.071754 & 0.000050991 & 0.05216 & 0.096386 & 33.87614877 \\
\hline 0.069476 & 0.000092320 & 0.054288 & 0.036145 & 4.76383342 \\
\hline 0.040906 & 0.000042369 & 0.062764 & 0.096386 & 33.87614877 \\
\hline 0.084172 & 0.000054474 & 0.052573 & 0.060241 & 13.23287061 \\
\hline 0.085823 & 0.000053972 & 0.051656 & 0.090361 & 29.77395888 \\
\hline 0.037732 & 0.000051439 & 0.051597 & 0.090361 & 29.77395888 \\
\hline 0.040156 & 0.000062870 & 0.051922 & 0.060241 & 13.23287061 \\
\hline
\end{tabular}

Table 6. MRPI calculation for each factor at a level.

\begin{tabular}{llcc}
\hline Level & Speed & Feed & Doc \\
\hline 1 & 11.71109 & 4.829998 & 4.829998 \\
2 & $\mathbf{2 2 . 0 3 2 7 3}$ & 16.73958 & 16.73958 \\
3 & 19.31999 & 22.03273 & 22.03273 \\
4 & 21.50341 & $\mathbf{3 0 . 9 6 4 9 2}$ & $\mathbf{3 0 . 9 6 4 9 2}$ \\
Max-Min & 10.32164 & 26.13492 & 26.13492 \\
\hline
\end{tabular}

A positive number is added to the Twr vector to convert into non-negative inputs without minimum the better criteria. In the DEAR (MCDM) technique, weights for SR, Vib, MRR, Twr responses are computed using equations (1)-(4) respectively. The ranking computed using equations (5)-(9) for each data point shown in Table 5. These computed MRPI are summed up for each input level for each output and summarized in Table 6. Maximum magnitude settings are chosen for high MRR, low: Twr, $\mathrm{SR}$, and vibrations. The optimal data set $(120 \mathrm{~m} / \mathrm{min}$, $0.2 \mathrm{~mm} / \mathrm{rev}, 1 \mathrm{~mm}$ ) using the DEAR method is found, and since no experimental value at this setting, verification is done via experimentation.
Though the recommended speed for dry machining is $60 \mathrm{~mm} / \mathrm{min}$, machining experiment conducted at $120 \mathrm{~mm} / \mathrm{min}$, for comparison, it is observed that the tool wear was very high and rapid, and the coating was pulled off the tool Figure 9. The experimentation results at optimal setting in dry, wet, and MQCL; MQCL application results in a $30 \%$ decrease of SR compared to dry and $13 \%$ decrease in SR compared to flood, as shown in Table 7. The results obtained are in line with reported works at $120 \mathrm{~m} /$ min and $0.2 \mathrm{~mm} / \mathrm{rev}$ dry, the tool wear was noted at a rate of $0.6 \mathrm{~mm}$ and in MQCL $0.4 \mathrm{~mm}$ [9]. The SR at $135 \mathrm{~mm} /$ min speed, $0.2 \mathrm{~mm} / \mathrm{min}$ feed, and $0.75 \mathrm{~mm}$ doc is reported as 2.2 microns and 2.45 microns with and without lubrication, respectively [4].

\section{Conclusion}

An attempt has been made to obtain optimal cutting variable settings while turning Ti6Al4V alloy in transition speed ranges [120-200 m/min] under the MQCL environment. The results were encouraging in speeds ranges $120-160 \mathrm{~m} / \mathrm{min}$ for considered doc $(0.25-1.0 \mathrm{~mm})$ and feed 

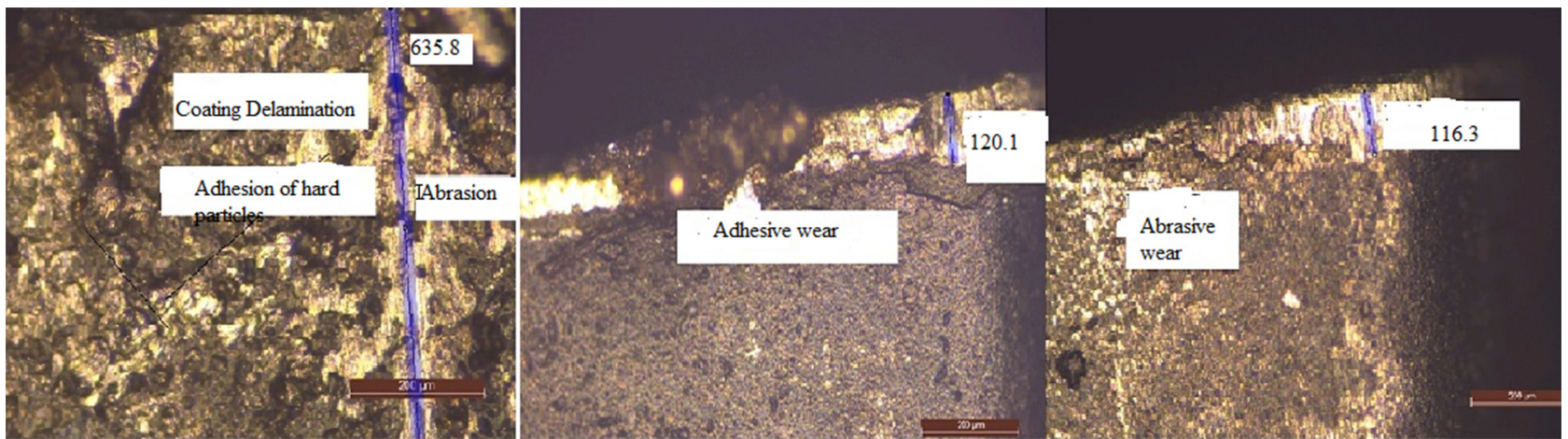

Fig. 9. Tool wear at the optimal setting for Dry, Flood and MQCL.

Table 7. confirmatory experiment at $(120 \mathrm{~m} / \mathrm{min}$ speed, $0.2 \mathrm{~mm} / \mathrm{rev}$ feed, $1 \mathrm{~mm}$ doc in dry, flood and MQCL environment).

\begin{tabular}{llll}
\hline Environment & SR(Microns) & Vibration (microns) & Tool Wear rate (Twr) \\
\hline MQCL & 1.69 & 44.7 & -6.9867 \\
Dry & 2.21 & 60.2 & -5.0120 \\
Flood & 1.92 & 46.5 & -6.8498 \\
\hline
\end{tabular}

rates $(0.05-0.2 \mathrm{~mm} / \mathrm{rev})$ compared to dry and flood cooling results from published literature. The effect of workpiece vibration was explored in the study. An MCDM technique DEAR is used to optimize tool wear, roughness, vibrations, and MRR simultaneously.

- Tool wear: The MQCL has proven to reduce the cutting temperatures in flank workpiece interaction zones. At speeds range between 80 and $160 \mathrm{~mm} / \mathrm{min}$ MQCL proved to be an adequate coolant and lubricant as the tool wear was less than dry and flood environment. For speeds beyond $160 \mathrm{~mm} / \mathrm{min}$, MQCL could not provide the necessary lubrication effect due to high temperatures; the lubricant contact with the surface is very less, and evaporation took place. The cutting speed has the most decisive influence on tool life, followed by feed rate.

- Vibrations: Since the spring back effect is proportional to the ratio of hardness and young's modulus of elasticity, the higher hardness and low elastic modulus of alloy results in deflection of the workpiece. The tool needs penetration to avoid deflection; high doc, in turn, increases friction and temperatures. Hence vibrations of the workpiece during turning of Ti6Al4V have an impact on tool wear and surface quality, and in this study effect of parameters on vibrations is analyzed. Feed rate is the most significant factor followed by doc. Vibrations and surface roughness exhibited a similar trend at speeds between 80 and $120 \mathrm{~m} / \mathrm{min}$.

- The feed is the most significant factor affecting surface quality in MQCL, and this is the same as literature published results.

- Optimization using the DEAR technique in MQCL was carried for the best parameter setting and resulted in cutting velocity $120 \mathrm{~m} / \mathrm{min}$, feed rate $0.2 \mathrm{~mm} / \mathrm{rev}$, and doc $1.0 \mathrm{~mm}$ for minimum tool wear, vibration, surface roughness, and maximum productivity. Experiments were conducted at this setting in dry, MQCL, and flood environment. Machining under MQCL environment resulted in a reduction of $30 \%$ SR compared to dry, and a $13 \%$ decrease in SR than flood environment. The tool wear rate is highest in dry conditions. At the optimal setting, the MQCL offered a $26 \%$ and $40 \%$ reduction in tool wear rate and vibrations then the dry environment.

Hence MQCL environment optimum parameters can be recommended at the speeds of $80 \mathrm{~m} / \mathrm{min}-160 \mathrm{~m} / \mathrm{min}$ at feeds of $0.1 \mathrm{~mm} / \mathrm{rev}-0.2 \mathrm{~mm} / \mathrm{rev}$ and doc $0.25-1.0 \mathrm{~mm}$ and optimum setting being $(120 \mathrm{~m} / \mathrm{min}, 0.2 \mathrm{~mm} / \mathrm{rev}, 1.0 \mathrm{~mm})$.

The nozzle position parameters like the distance between nozzle and tool-tip, the angle of spray measured in the feed direction influence the lubricant penetration and cooling performance. The effect of nozzle position parameters, spray pressure, and exit-temperatures on responses can be investigated in further studies. The variation of the microhardness of the workpiece and chip can be examined in further studies. Nano additives in lubricant and their effectiveness while machining at speeds of $120-200 \mathrm{~m} / \mathrm{min}$ needs to be studied for Ti6Al4 under MQCL. Additionally, hybrid techniques, like a combination of MQCL and Cryogenic cooling, and its effects on vibrations, temperatures, chip morphology, can be investigated. Microstructure analysis of chips can help understand the reactions during the process and type of wear mechanism.

\section{References}

1. C. Veiga, J.P. Davim, A. Loureiro, Properties and applications of Titanium alloys: a brief review properties and applications of titanium, properties, and applications of titanium, Rev. Adv. Mater. Sci. 32 (2012) 133-148 
2. A.R. Machado, J. Wallbank, Machining of titanium and its alloys: a review, Proc. IMechE 204 (2005) $53-60$

3. M. Armendia, A. Garay, L.M. Iriarte, P.J. Arrazola, Comparison of the machinabilities of Ti6Al4V and TIMETAL using uncoated WC-Co tools, J. Mater. Proc. Technol. 210 (2010) 197-203

4. J. Paulo Davim, Machining of titanium alloys, Springer, 2014

5. S. Sharif, E.A. Rahim, Performance of coated-and uncoated carbide tools when drilling titanium alloy-Ti-6Al4V, J. Mater. Proc. Technol. 185 (2007) 72-76

6. M. Younas, S. Jaffery, M. Khan, M. Ali khan, R. Ahmad, A. Mubashar, L. Ali, E. Tascioglu, A. Gharibi, Y. Kaynak, Multi-objective optimization for sustainable turning Ti6Al4V alloy using grey relational analysis (GRA) based on analytic hierarchy process (AHP) high speed machining of near-beta titanium Ti-5553 alloy under various cooling and lubrication conditions, Int. J. Adv. Manuf. Technol. 102 (2019) 4257-4271

7. G.D. Mello, P. Srinivas, A. Prashant, Surface roughness analysis in high speed turning of Ti-6Al-4V using coated carbide inserts: experimental and modeling studies, Tribol. Ind. 40 (2018) 457-476

8. S. Pervaiz, I. Deiab, A. Rashid, M. Nicolescu, Minimal quantity cooling lubrication in turning of Ti6Al4V: influence on surface roughness, cutting force and tool wear, Proc. IMechE Part B 1 (2015) 1-17

9. S. Ranti Oke, G. Seun Ogunwande, M. Onifade, E. Aikulola, E. Dolapo Adewale, O. Emmanuel Olawale, B. Ebun Ayodele, F. Mwema, J. Obiko, M.O. Bodunrin, An overview of conventional and non-conventional techniques for machining of titanium alloys, Manufactur. Rev. 7 (2020) 34

10. B. Prianka, Zaman, S. Saha, N. Ranjan Dhar, Hybrid Taguchi-GRA-PCA approach for multi-response optimization of turning process parameters under HPC condition, Int. J. Mach. Mach. Mater. 22 (2020) 281-308

11. M. Mia, M.A. Khan, N.R. Dhar, High-pressure coolant on flank and rake surfaces of tool in turning of Ti-6Al-4V: investigations on surface roughness and tool wear, Int. J. Adv. Manuf. Technol. 90 (2017) 1825-1834

12. M. Mia, M.A. Khan, N.R. Dhar, Study of surface roughness and cutting forces using ANN, RSM, and ANOVA in turning of Ti- $6 \mathrm{Al}-4 \mathrm{~V}$ under cryogenic jets applied at flank and rake faces of coated WC too, Int. J. Adv. Manuf. Technol. 93 (2017) 975-991

13. M. Mia, M.A. Khan, S.S. Rahman, N.R. Dhar, Monoobjective and, multi-objective optimization of performance parameters in high-pressure coolant assisted turning of Ti-6Al-4V, Int. J. Adv. Manuf. Technol. 90 (2017) 109-118

14. B. Słodki, Z. Wojciech, G. Struzikiewicz, Turning titanium alloy, grade 5 ELI, with the implementation of high pressure coolant, Materials 12 (2019)

15. M.V. Ramana, G.K. Mohan Rao, D.H. Rao, Optimization and effect of process parameters on tool wear in turning of titanium alloy under different machining conditions, Int. J. Mater. Mech. Manuf. 2 (2014) 272-277

16. I. Deiab, S.W. Raza, S. Pervaiz, Analysis of lubrication strategies for sustainable machining during turning of titanium Ti-6Al-4Valloy, Proc. CIRP 17 (2014) 766-771
17. D. Mark Benjamin, V.N. Sabarish, M.V. Hariharan, D. Samuel Raj, On the benefits of sub-zero air supplemented minimum quantity lubrication systems: an experimental and mechanistic investigation end milling of Ti-6-Al-4-V alloy, Tribol. Int. (2017), doi: 10.1016/j.triboint.2017.11.021

18. K. Arun Vikram, V.V.K. Lakshmi, A.M. Venkat Praveen, Evaluation of process parameters using GRA while machining low machinability material in dry and wet conditions, Mater. Today Proc. 5 (2018) 25477-25485

19. V.R. Vaddi, V.K. Sridhar Reddy, Ch. Pogaku, S.K. Bushaboina, Optimization of electrical discharge machining of titanium alloy (Ti-Al-4V) using the Taguchi-Dear method, SAE Technical Paper (2018) 28-0032

20. S.H.I. Jeffery, P.T. Mativenga, Wear mechanisms analysis for turning Ti-6Al-4V - towards the development of suitable tool coatings, Int. J. Adv. Manuf. Tech. 58 (2012) 479-493

21. Y. Tamerabeta, M. Briouaa, M. Tamerabeta, S. Khoualdia, Experimental investigation on tool wear behavior and cutting temperature during dry machining of carbon steel SAE 1030 using KC810 and KC910 coated inserts, Tribol. Ind. 40 (2018) 52-65

22. N. Kumar Sahu, A.B. Andhare, Multi-objective optimization for improving machinability of Ti-6Al-4V using RSM and advanced algorithms, J. Computat. Des. Eng. 6 (2019) $1-12$

23. K.N.S.R. Ganesh, Kantharaj, S. Kumar, Multi-response optimization of Ti-6Al-4V milling using AlCrN/TiAlN coated tool under cryogenic cooling, J. Product. Syst. Manufactur. Sci. 1 (2020) 29-41

24. N. Li, Y. Chen, D. Kong, Multi-response optimization of Ti-6Al-4V turning operations using Taguchi-based grey relational analysis coupled with kernel principal component analysis, Adv. Manuf. 7 (2019) 142-154

25. S. Ranti Oke, G. Seun Ogunwande, M. Onifade, E. Aikulola, E. Dolapo Adewale, O. Emmanuel Olawale, B. Ebun Ayodele, F. Mwema, J. Obiko, M. Oluwatosin Bodunrin, An overview of conventional and non-conventional techniques for machining of titanium alloys, Manufactur. Rev. 7 (2020) 34

26. S. Jafferry, P.T. Mativegan, Assessment of the machinability of Ti-6AL-4V alloy using wear map approach, Int. J. Adv. Manuf. Technol. 40 (2009) 687-696

27. T. Muthuramlingam, S. Vasanth, P. Vinoth Kumar, T. Geethapriya, M. Mohammed Rabik, Multi-criteria decision making of abrasive flow oriented process parameters in abrasive jet machining using Taguchi-dear methodology, Silicon (2018) 2015-2021

28. S. Pervaiz, A. Rashid, I. Deiab, C.M. Nicolescu, An experimental investigation on effect of minimum quantity cooling lubrication (MQCL) in machining titanium alloy (Ti6Al4V), Int. J. Adv. Manuf. 87 (2016) 1371-1386

29. S. Sharif, E.A. Rahim, Performance of coated-and uncoated carbide tools when drilling titanium alloy- Ti-6Al4V, J. Mater. Proc. Technol. 185 (2007) 72-76

30. S. Sharma Vishal, M. Dogra, N.M. Suri, Cooling techniques for improved productivity in turning, Int. J. Mach. Tools Manufact. 49 (2009) 435-453

31. B.S. Prasad, J.U. Rao, A. Gopala Krishna, Analysis of vibration signals to quantify displacement amplitude in the 
monitoring of vibration-assisted turning, Proc. Inst. Mech. Eng. E 233 (2019) 35-47

32. Z.A. Zoya, R. Krishnamurthy, The performance of CBN tools in the machining of titanium alloys, J. Mater. Process. Technol. 100 (2000) 80-86

33. https://www.kennametal.com/CatalogsLiterature/Indus try\%20Solutions/Titaniummaterial_Machining_guide_ Aerospace
34. H. Schulz, T. Moriwaki, High-speed machining, CIRP Ann. 41 (1992) 637-643

35. Y. Fan, Z. Hao, M. Zheng, S. Yang, Wear characteristics of cemented carbide tool in dry machining Ti-6Al-4V, Mach. Sci. Technol. 20 (2016) 249-261

36. M. Younas, Tool wear progression, and its effect on energy consumption in turning of titanium alloy (Ti-6Al-4V). Mech. Sci. 2 (2019) 373-382

Cite this article as: Vennela V. K. Lakshmi, Kambagowni Venkata Subbaiah, Arun Vikram Kothapalli, Kilparthi Suresh, Parametric optimization while turning Ti-6Al-4V alloy in Mist-MQCL (Green environment) using the DEAR method, Manufacturing Rev. 7, 38 (2020) 